\title{
Crowdsourcing the Disaster Management Cycle
}

Sara E Harrison, University of Waterloo, Waterloo, Canada

Peter A Johnson, University of Waterloo, Waterloo, Canada

\begin{abstract}
Crowdsourcing is a communication platform that can be used during and after a disastrous event. Previous research in crisis crowdsourcing demonstrates its wide adoption for aiding response efforts by non-government organizations and public citizens. There is a gap in understanding the government use of crowdsourcing for emergency management, and in the use of crowdsourcing for mitigation and preparedness. This research aims to characterize crowdsourcing in all phases of the disaster management cycle by government agencies in Canada and the USA. Semi-structured interviews conducted with 22 government officials from both countries reveal that crisis crowdsourced information is used in all phases of the disaster management cycle, though direct crowdsourcing is yet to be applied in the pre-disaster phases. Emergency management officials and scholars have an opportunity to discover new ways to directly use crowdsourcing for mitigation and preparedness.
\end{abstract}

\section{KEYWORDS}

Crisis Crowdsourcing, Crowdsourcing, Emergency Management, Government, Information Communication Technology, Social Media

\section{INTRODUCTION}

The use of the Internet in emergency operations has opened up new opportunities for improving communication during a crisis. Over the past decade, crowdsourcing, that is the volunteer-generated, decentralized contribution of information online, has become essential to emergency response efforts, as citizens experiencing a crisis often spontaneously share information about current conditions (Burns \& Shanley, 2012; Haworth \& Bruce, 2015; Liu, 2014; Starbird, 2012). In this paper, the authors focus specifically on two broad approaches to crowdsourcing: active and passive. However, the literature contains a wealth of crowdsourcing typologies and approaches that are outside of the scope of this paper, but are worth noting (for a detailed review see (Brabham, 2013; Estelles-Arolas \& GonzalezLadron-de-Guevara, 2012; Hossain \& Kauranen, 2015; Lauriault \& Mooney, 2014). Traditionally, crisis crowdsourcing efforts take the form active crowdsourcing, in which specialized platforms and applications have been developed for users to actively contribute to a call for information (Loukis \& Charalabidis, 2015; Tong et al., 2014). These platforms are usually developed and implemented by members of the affected public (e.g. Scipionus during Hurricane Katrina, the map-mashups during the 2007-2009 Santa Barbara wildfires) or by non-governmental organizations (NGO's) such as 
Ushahidi (Hiltz et al., 2014; Meier, 2012; Roche et al., 2011). The purpose of such platforms is to improve disaster response and resource allocation based on real-time reports from disaster victims that can be used to facilitate coordination with responders (Roche et al., 2011; Zook et al., 2010).

More recently, passive crowdsourcing via social media has emerged as a tool to communicate information in times of emergency (Charalabidis et al., 2014; Kaplan and Haenlein, 2010). Social media is increasingly being used by both NGO's and government emergency management agencies to determine public sentiment and reaction to an event (Bird et al., 2012; Flew et al., 2015; Fraustino et al., 2012; Laskey, 2013; Latonero \& Shklovski, 2011; Lindsay, 2011; Taylor et al., 2012; Virtual Social Media Working Group and DHS First Responders Group, 2014). It is evident that the multidirectional flows of communication and information that crisis crowdsourcing online platforms facilitates can make response and recovery efforts more efficient and effective (Roche et al., 2011).

Despite the wealth of literature on crowdsourcing for emergency response, there is very little research on government use of crowdsourcing for emergency management. Given this focus on the individual contributor, rather than a government agency that would host a crowdsourcing platform, it is possible that the emergence of crowdsourcing during a crisis can be framed as a response to the failure of governments to act swiftly (Johnson and Sieber, 2013). In a study on bushfire safety in Australia, Brady and Webb (2013) suggest that unofficial community bushfire websites existed due to a gap in official online services. Though government agencies have been generally slow in adopting online crowdsourcing technologies, several agencies in the USA, Canada, Australia, and Europe have begun experimenting with these systems (Beaulieu et al., 2008; Koch et al., 2011; Lodge \& Wegrich, 2014). Latonero and Shklovski (2011) describe the use of social media from the perspective of emergency management professionals as previous studies focused primarily on the use and application of crowdsourcing and social media information for response and rescue. Through a case study of the Los Angeles Fire Department, Latonero and Shklovski determined that the Public Information Officer within the department was the sole driver for the use of social media, specifically Twitter, for real-time interactivity during an event. The case study was limited in determining whether other emergency management agencies follow similar processes for integrating social media into their operations (Latonero \& Shklovski, 2011). This limitation was addressed two years later in a project funded by the National Emergency Management Association (NEMA) in the USA to determine the level of adoption and use of social media by government emergency management agencies at the state, county, and municipal levels (San Su et al., 2013). The results show many agencies are using social media in their emergency management operations, however many agencies lack specific policies (San Su et al., 2013). In 2014, Hiltz et al. interviewed emergency management professionals to identify keys "barriers and wish lists" when adopting social media into government emergency management operations in the USA.

Outside of the USA, studies for government use of crisis crowdsourcing and social media are beginning to emerge. In Canada, the Defence Research and Development Canada (DRDC) Centre for Security Science (CSS) in partnership with the Calgary Emergency Management Agency (CEMA) held a workshop on Social Media for Emergency Management (SMEM) with emergency management professionals from various realms (e.g. volunteers, first responders, public servants, and NGO's) to facilitate discussions around the integration of social media in emergency management operations in Canada (Kaminska et al., 2013). More recently, in Australia a study by Haworth (2016) was conducted to identify the impacts of crisis crowdsourcing in Australian government emergency operations.

These emerging initiatives illustrate the need for identifying the ways in which crowdsourcing can support all phases of disaster management, including mitigation and preparedness, rather than simply the response phase (Haworth \& Bruce, 2015). The goal of this paper is to determine the use of crowdsourcing technologies within government, identifying how crowdsourcing links to all phases of disaster management. Drawing on interviews with emergency management staff in the USA and Canada, we characterize the current use of crisis crowdsourcing by these government agencies, and uncover how crowdsourcing is currently applied in all phases of the disaster management cycle. 


\section{CRISIS CROWDSOURCING}

The development of a crowdsourcing platform for emergency response typically happens spontaneously, during or immediately after an adverse and impactful event (Burns and Shanley, 2012; Liu, 2014; Starbird, 2012). In addition, such platforms are developed and implemented by members of the affected public or by non-governmental organizations (NGO's) (Roche et al., 2011). The NGO, Ushahidi, became a major communication resource in the wake of the Haitian earthquake disaster in 2010: It is described as a resource and information sharing platform that allows users to send in information about a specific event unravelling on the ground via SMS, e-mail, or online form, for others to view (Roche et al., 2011). Another notable example of crisis crowdsourcing, the map mashups for the Santa Barbara wildfires of 2007 to 2009, further demonstrate how citizens built their own communication tools as a response to inaccurate government updates (Goodchild \& Glennon, 2010).

Little research is available on government use of crowdsourcing for emergency management. Johnson and Sieber (2013) described emergency response as the most "prominent" use of VGI, though not by governments. Government agencies may be slow in adopting crisis crowdsourcing because of a lack of awareness or understanding of the benefits. Since the crisis crowdsourcing literature focuses on the use of it by NGO's and citizens and its associated benefits, it can be difficult for government agencies to determine whether adopting it into their own operations offers the same or different benefits. Interviews with government emergency managers identified several barriers to government use of crisis crowdsourcing, from a lack of personnel and proper training, policies and procedures blocking social media use, to the trustworthiness of the crowdsourced information (Hiltz et al., 2014). Additional challenges identified by Haworth (2016) include the digital divide, liability around accepting unverified information, and proper management of the information. Despite these challenges, some government agencies are using crowdsourcing and VGI for emergency management practices. Examples of these practices have been documented in the literature and are summarised in Table 1.

There is a growing literature focusing on the potential for social media, as a form of passive crowdsourcing, to enhance 911 emergency systems. In this way, social media acts as a crowdsourcing conduit for early detection, to determine public sentiment and reaction to response agencies' efforts, to enhance situational awareness, to coordinate amongst social media users, and to accelerate damage estimation processes based on information being posted by social media users (Avvenuti et al., 2016; Bird et al., 2012; Flew et al., 2015; Fraustino et al., 2012; Lindsay, 2011; Starbird and Palen, 2011). Several studies into the use of social media during crisis events show that social media offers emergency managers with an opportunity to "use citizens as data reporters" (Starbird \& Stamberger, 2010). Similarly, geo-located reports from social media can be used to populate a crowdsourcing web-map application to support crisis recovery and aid efforts (Gao et al., 2011). Most recently, the Canadian government participated in a resiliency experiment with the American government to assess the performance of social media for cross-border exchange of information during a simulated hurricane event (Cotter et al., 2015). It was found that social media can improve recovery operations, yet agencies are not fully exploiting these tools.

\section{THE DISASTER MANAGEMENT CYCLE}

When a disaster or emergency strikes a region, quick and effective decision-making is of the utmost importance. Crisis crowdsourcing technologies show potential to support this decision-making, within all four phases of the disaster management cycle; mitigation, preparedness, response, and recovery (see Figure 1). The disaster management cycle is a continuous process that moves through phases of reducing risk and exposure to hazards (i.e. mitigation) and planning and preparing for oncoming hazards and preventing a disaster (i.e. preparedness), to phases of reducing impacts of a disaster through response efforts and search and rescue (i.e. response) and restoration through clean- 
Table 1. Summary of active crisis crowdsourcing applications implemented by government agencies

\begin{tabular}{|c|c|c|c|c|}
\hline Agency & Country & $\begin{array}{c}\text { Application } \\
\text { Name }\end{array}$ & $\begin{array}{c}\text { Date } \\
\text { Implemented }\end{array}$ & Description \\
\hline $\begin{array}{l}\text { USGS } \\
\text { (Federal) }\end{array}$ & USA & $\begin{array}{l}\text { Did You Feel } \\
\text { It? (DYFI?) }\end{array}$ & 1997 & $\begin{array}{l}\text { The first "fully automated earthquake detection } \\
\text { intensity system." Citizens send in earthquake } \\
\text { observations online, which are used for early } \\
\text { detection and data analysis (Wald et al., 1999, 2011). }\end{array}$ \\
\hline $\begin{array}{l}\text { Miami-Dade } \\
\text { County } \\
\text { (County) }\end{array}$ & USA & $\begin{array}{l}\text { Snapshot } \\
\text { Damage } \\
\text { Assessment \& } \\
311\end{array}$ & 2007 & $\begin{array}{l}\text { The county receives online reports of damage and } \\
311 \text { telephone calls to enhance their situational } \\
\text { awareness during an emergency event (Castellanos et } \\
\text { al., 2013; Schellong \& Langenberg, 2007). }\end{array}$ \\
\hline $\begin{array}{l}\text { USGS } \\
\text { (Federal) }\end{array}$ & USA & $\begin{array}{l}\text { Tweet } \\
\text { Earthquake } \\
\text { Dispatch (TED) }\end{array}$ & 2011 & $\begin{array}{l}\text { An earthquake detection procedure that relies on } \\
\text { Twitter data alone. The procedure allows for rapid } \\
\text { earthquake detection and a qualitative assessment of } \\
\text { events (Earle et al., 2012). }\end{array}$ \\
\hline $\begin{array}{l}\text { USGS } \\
\text { (Federal) }\end{array}$ & USA & Did You See it? & 2012 & $\begin{array}{l}\text { A reporting application mirroring the DYFI? model } \\
\text { to allow users to report instances of landslides } \\
\text { experienced and witnessed (Baum et al., 2014). }\end{array}$ \\
\hline $\begin{array}{l}\text { FEMA } \\
\text { (Federal) }\end{array}$ & USA & FEMA App & 2013 & $\begin{array}{l}\text { The application provides weather alerts, emergency } \\
\text { preparation tips, other disaster resources, and the } \\
\text { ability for citizens to submit disaster photos onto a } \\
\text { pubic web-map. The map is universally accessible, } \\
\text { with no restrictions, thus allowing all emergency } \\
\text { managers to view the information (Adamski, 2013). }\end{array}$ \\
\hline $\begin{array}{l}\text { Department } \\
\text { of Energy } \\
\text { (Federal) }\end{array}$ & USA & Lantern Live & 2014 & $\begin{array}{l}\text { During an emergency or power outage, citizens can } \\
\text { report the operational status of fuel stations, for } \\
\text { other citizens to determine where fuel is available } \\
\text { and identify where power outages are occurring } \\
\text { (Department of Energy, 2014). }\end{array}$ \\
\hline $\begin{array}{l}\text { USGS } \\
\text { (Federal) }\end{array}$ & USA & iCoast & 2014 & $\begin{array}{l}\text { "Digital volunteers" compare before and after aerial } \\
\text { photos of Hurricane Sandy and classify changes } \\
\text { along the US coast caused by the hurricane. The } \\
\text { application was designed to validate predictive } \\
\text { models of coastal change (Liu, 2014). }\end{array}$ \\
\hline $\begin{array}{l}\text { Grundy } \\
\text { County } \\
\text { (County) }\end{array}$ & USA & $\begin{array}{l}\text { Grundy EMA } \\
\text { App }\end{array}$ & 2015 & $\begin{array}{l}\text { The application educates citizens on local hazards } \\
\text { and emergency practices, sends out alerts, and } \\
\text { allows citizens to send in reports of damage after a } \\
\text { severe weather event. The information gathered by } \\
\text { the county is reported back to the National Weather } \\
\text { Service (Litchfield, 2015). }\end{array}$ \\
\hline
\end{tabular}

up and reconstruction (i.e. recovery) (Poser \& Dransch, 2010). During the response and recovery phases, timely and accurate information is crucial to managing an unfolding event (Morton \& Levy, 2011; Zhang et al., 2002), as such, crisis crowdsourcing is typically used in the response phase of an unfolding disaster. For example, Scipionus, a citizen-led crowdsourcing platform that emerged in the aftermath of Hurricane Katrina, became a crucial communication tool for victims of the hurricane to connect with each other and locate loved ones when traditional communication infrastructure failed (Roche et al., 2011). Additionally, all but one of the applications listed in Table 1 are used directly for response and recovery efforts. The only application that is not directly used in the immediate aftermath of a disaster is iCoast, which can be accessed by citizens any time, yet it uses imagery of before and after the hurricane disasters. 
Figure 1. The Disaster Management Cycle and the four phases. The cycle is split into two general periods, the pre-disaster period with the mitigation and preparedness phases, and the post-disaster period, with the response and recovery phases.

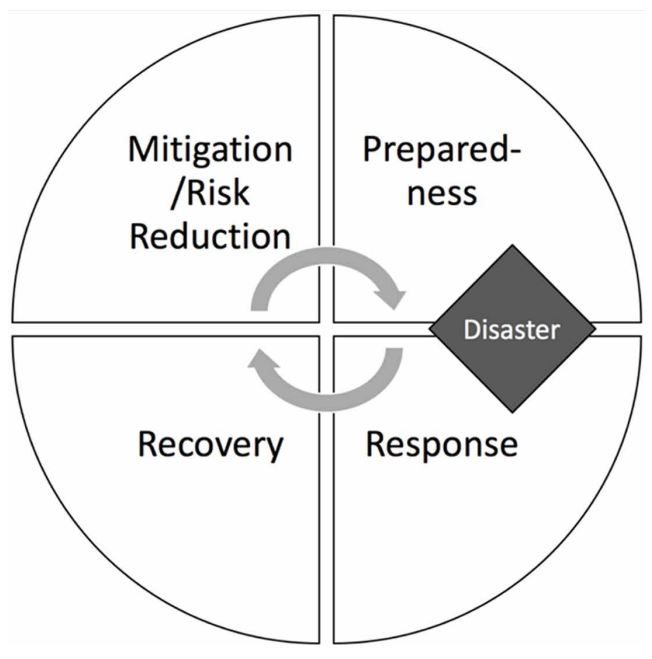

In these instances, crowdsourcing is used to gather information about current ground conditions to improve decision making, however there is a clear gap in understanding the role crowdsourcing can play in other phases of the disaster management cycle, chiefly mitigation and preparedness (Haworth \& Bruce, 2015). Much of the focus within the disaster management realm has shifted to these pre-disaster phases rather than the post-disaster phases of response and recovery (Chikoto et al., 2013; Christoplos et al., 2001; Paton, 2003; Paton \& Johnston, 2001), however the focus on crisis crowdsourcing remains in the response and recovery phases. To fill this gap, interviews with emergency management officials aims to understand how crowdsourced information can feed into the mitigation and preparedness phases.

\section{Characterizing Current Government Use of Crisis Crowdsourcing}

To assess how governments are currently using crowdsourcing, we conducted semi-structured telephone and face-to-face interviews with government officials in both Canada $(n=15)$ and the United States $(n=7)$. Interviewees were asked to assess their current tools and processes, and to discuss the overall performance of crowdsourcing within their agency. Interviewees were selected based on their roles in emergency management, and involvement with existing crowdsourcing projects. In total, 48 officials were contacted for participation in the study from Canada and 52 from the United States. From this sample pool, there was a $31 \%$ response rate from Canadian officials, and a $14 \%$ response rate from officials in the United States (Table 2). Interviewees included community emergency management coordinators (CEMC), public safety director, oceanographer, seismologists, warning preparedness meteorologist, strategic initiatives coordinator, retired fire chief, senior systems analysts, manager of emergency planning, director of emergency services, director of operations, and communications and marketing officials. Interviews were audio-recorded, transcribed, and coded based on interview script themes.

\section{Types of Crisis Crowdsourcing Tools and Implementation}

Participating government agencies from both Canada and the United States use several approaches to emergency information communication (Figure 2). Some methods are traditional approaches that use telephones, and others are online, using social media or dedicated crowdsourcing applications. Though respondents from both countries were heavy users of social media, Canadian governments 
Table 2. Number of interviewees from each level of government in Canada and the USA

\begin{tabular}{|l|l|l|l|l|l|l|}
\hline & \multicolumn{3}{|c|}{ Canada } & \multicolumn{3}{c|}{ USA } \\
\cline { 2 - 8 } & Contacted & Participated & $\begin{array}{c}\text { Response } \\
\text { Rate (\%) }\end{array}$ & Contacted & Participated & Response Rate (\%) \\
\hline Local & 17 & 5 & 29 & 10 & 2 & 20 \\
\hline County & 26 & 6 & 27 & 8 & 1 & 13 \\
\hline $\begin{array}{l}\text { Provincial/ } \\
\text { State }\end{array}$ & 4 & 2 & 50 & 26 & 0 & 0 \\
\hline Federal & 1 & 1 & 100 & 7 & 4 & 57 \\
\hline Total & 48 & 14 & 31 & 51 & 7 & 14 \\
\hline
\end{tabular}

Figure 2. Methods used by government agencies to collect information from the public for emergency management

\section{Emergency Information Communication Methods used by Government Agencies in Canada and the USA}

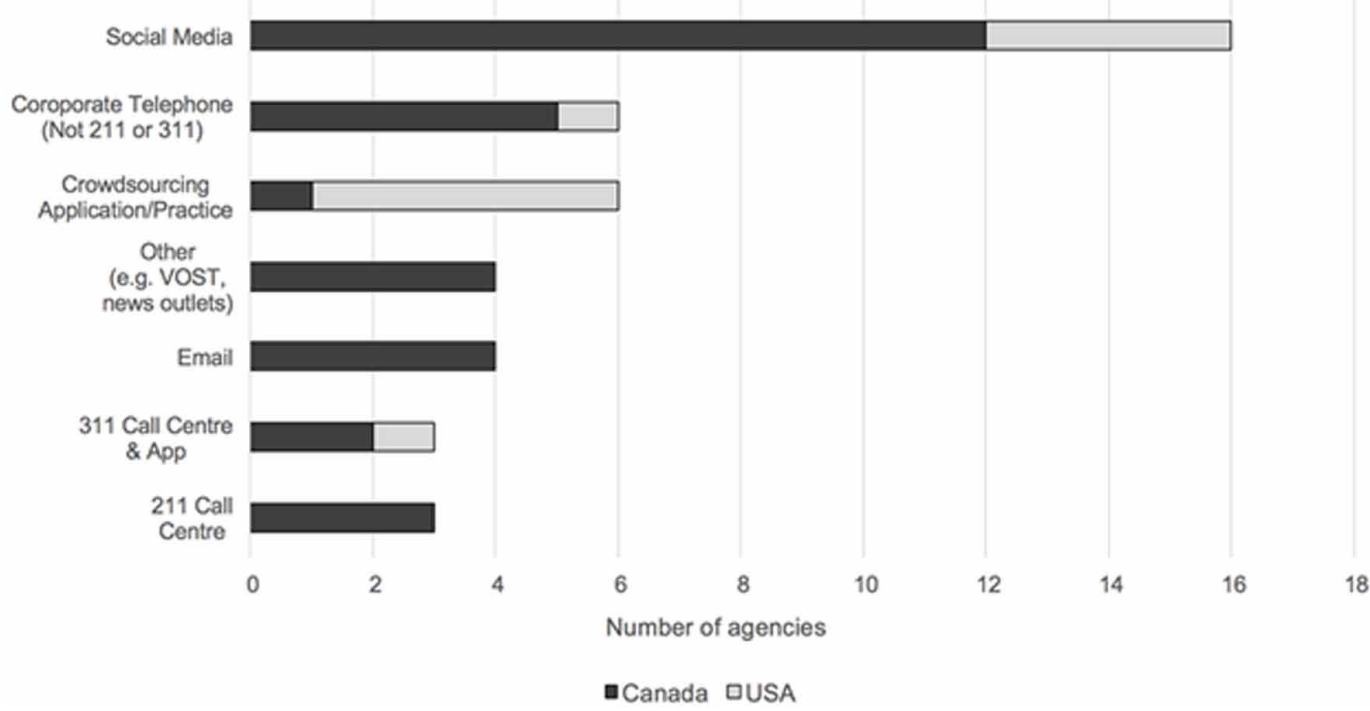

tended to favor traditional methods of communication, such as corporate telephone, 211 service, and 311 call centers. Given that crowdsourcing is a new phenomenon, it is not surprising that traditional methods like phone calls and call centers (e.g. 211 and 311) and email are still used. The entrenchment of these forms of communication was considered a product of the training that officials have, and that this information could be better verified, compared to social media. As indicated by two city-level officials from Canada, a Customer Service Supervisor and a Community Emergency Management Coordinator, respectively:

Phone call is still the best, it's still king because we have the person on the line and we can talk to them. And we're trained on how to deal when we have a person with us. We don't necessarily have training on how to get the most information out of social media and email. (Interviewee O, 2015) 
The [reports] that are called in are, for a better word, validated, you know we've got the name, we've got a phone number, we may have an email address, we have a way of getting back to the resident. (Participant K, 2015)

This finding contrasts to the US agencies, that employed dedicated crowdsourcing applications, considered to be unique interfaces that are created for active crowdsourcing, as opposed to passive social media-based crowdsourcing efforts. In total, only one participating Canadian agency used a dedicated crowdsourcing application, compared to five of the seven participating US agencies.

In addition to the types of methods used, the implementation of these methods differed between the Canadian and American agencies (see Table 3). For example, active crowdsourcing is primarily used by the participating federal government agencies in the USA. Alternatively, the participating agencies in Canada tend to use passive crowdsourcing methods (e.g. harvesting data from social media). Participating municipal agencies in Canada still relied on traditional methods of emergency information communication, such as corporate phone lines and call centers.

Results from interviews suggest that active crowdsourcing methods are predominantly used by federal-level agencies in both countries. For example, in Canada, the only federal agency to participate in the study was developing an active crowdsourcing model for collecting severe weather reports from trained weather watchers. Comparably, in the USA, the active crowdsourcing applications were open to the public. Passive crowdsourcing through social media was heavily used by participating government agencies in both Canada and the USA. Several uses of social media were described, with some agencies using social media for monitoring and harvesting information, while others used it for alerts. One interviewee from the provincial level in Canada outlined five reasons why their government used social media:

Table 3. Summary of emergency crowdsourcing efforts used by participating agencies in Canada and the USA. *No data is available for state level governments in the USA because none could be recruited.

\begin{tabular}{|c|c|c|c|c|}
\hline & & Canada & USA & Summary \\
\hline \multirow{4}{*}{$\begin{array}{l}\text { Active } \\
\text { Crowdsourcing }\end{array}$} & Federal & CANWARN & $\begin{array}{l}\text { Did You Feel It? } \\
\text { iCoast }\end{array}$ & \multirow{4}{*}{$\begin{array}{l}\text { The USA is leading the way in active crowdsourcing } \\
\text { adoption for emergency management with two active } \\
\text { crowdsourcing methods implemented at the federal level, } \\
\text { and one at the county level. In Canada, one active method } \\
\text { was adopted at the federal level, yet contributors to this } \\
\text { method still require training. One city level agency is } \\
\text { working towards active crowdsourcing through a new } 311 \\
\text { mobile application. }\end{array}$} \\
\hline & $\begin{array}{l}\text { Provincial/ } \\
\text { State }\end{array}$ & None & $\mathrm{N} / \mathrm{D}^{*}$ & \\
\hline & County & None & $\begin{array}{l}\text { Snapshot Damage } \\
\text { Assessment }\end{array}$ & \\
\hline & City & 311 App & None & \\
\hline \multirow{4}{*}{$\begin{array}{l}\text { Passive } \\
\text { Crowdsourcing }\end{array}$} & Federal & Social Media & $\begin{array}{l}\text { Twitter Earthquake } \\
\text { Dispatch Project } \\
\text { Virtual Social Media } \\
\text { Working Group }\end{array}$ & \multirow{4}{*}{$\begin{array}{l}\text { Passive crowdsourcing through social media is heavily } \\
\text { used in both countries, at all levels of government. }\end{array}$} \\
\hline & $\begin{array}{l}\text { Provincial/ } \\
\text { State }\end{array}$ & Social Media & N/D* & \\
\hline & County & Social Media & Social Media & \\
\hline & City & Social Media & Social Media & \\
\hline \multirow{4}{*}{ Other } & Federal & None & None & \multirow{4}{*}{$\begin{array}{l}\text { Agencies in Canada are still heavily reliant on non- } \\
\text { crowdsourcing methods for collecting emergency } \\
\text { information from the public. Call centres and corporate } \\
\text { telephone lines are the preferred method amongst lower- } \\
\text { tiered agencies for communicating with citizens. }\end{array}$} \\
\hline & $\begin{array}{l}\text { Provincial/ } \\
\text { State }\end{array}$ & None & N/D* & \\
\hline & County & 211 Call Centre & 311 Call Centre & \\
\hline & City & 311 Call Centre & None & \\
\hline
\end{tabular}


1. To evaluate the public's perception of the official emergency information being released;

2. To identify and help dispel rumors that could jeopardize public safety;

3. To identify threats to the agency's reputation that can impede the ability to respond to an incident, e.g. criticism from influential agencies;

4. To isolate calls for assistance on social networks and forward them to 911;

5. To gather information that will provide situational awareness.

From the interview responses, there was a progressive trend in tool selection, where agencies start using social media as a one-way information tool to send out information and alerts to the public:

Social media is a very valid tool in providing emergency information that's prompt, accurate, and allows people to take the necessary steps to protect themselves and their families. You know, it allows us to update those affected almost instantaneously, it's faster than a web post, it's faster than distributing a news release from the media. (Interviewee H, 2015)

When asked what influenced an agency's decision to adopt social media into their emergency management agency, one county-level CEMC replied:

Initially getting into social media, the argument that won it for us was the same argument that was used a hundred years ago when we convinced council to let us have a telephone, right. If that's how people are communicating, then that's how we need to communicate with them. (Interviewee A, 2015)

Next, agencies start monitoring social media for information control, for dispelling rumors, and to determine the public's perception of and response to the official information being sent out:

Because we were using social media extensively then and we knew it was important to be monitoring, not only what was happening with our information, was it being retweeted or shared on Facebook, but also to be able to respond and to monitor messages that were coming in on social media, either in response to our information or about the event. (Interviewee P, 2015)

So basically, way back probably even in 2011, the initial ideas came up and we basically wanted to develop the capacity to monitor, to kind of gain that situational awareness and be able to detect rumours and kind of determine how effective our messaging is when we did put out Tweets or whatever other platforms we were using at the time. (Interviewee M, 2015)

Finally, agencies use social media as a two-way communication tool, to send out alerts and to receive reports from citizens. One city-level Customer Service Supervisor from Canada described their transition from using social media for information dissemination to collecting reports from it:

Customer service, or our involvement in that has only been for the last year, because primarily it was used here at the town for just information out, you know, pushing information out, and we just have been flirting with, you know, receiving information, receiving complaints, receiving this, so on and so on. (Interviewee O, 2015)

It became clear from the interviews that agencies were at different levels of maturity in their use of social media. For example, one county-level official from Canada described that their agency first used social media for information dissemination and soon realized the value of monitoring social media to check how their information was being received and to monitor incoming messages, with social media monitoring now an official role in the agency's Emergency Operations Centre (EOC). 
Yet, in another county-level agency from Canada, the participating CEMC noted that their agency had yet to officially endorse social media for communication purposes, and were only considering it for information dissemination purposes.

\section{Crisis Crowdsourcing Impacts for Government Emergency Management}

Effective communication is critical in emergency management operations. Crowdsourcing and social media offer new ways to enhancing this communication. Interviewees identified several ways in which crisis crowdsourcing can improve communication and government emergency management (see Table 4).

Five areas of improvements or benefits of crisis crowdsourcing were described by the interviewees. With respect to government transparency and accountability, crowdsourcing can increase trust of citizens in their government by publicizing the information gathered by the agency and showing the citizens what the information is used for. Crowdsourcing also offers educational benefits by raising awareness about nearby hazards.

Crowdsourcing and social media can improve communication by offering a new avenue to connect with citizens, as described by a county level emergency manager in Canada:

I can go back to our Facebook page two years ago during our winter storm emergency, where we had somebody post on there, 'this was the best dissemination of information by a government agency ever,'... And we're pretty proud of that because we did work very hard to use social media to communicate with the affected public. (Interviewee A, 2015)

Citizens can share their own stories and experiences with their government, knowing that their information is useful, as described by a US federal level Research Geophysicist about their active crowdsourcing application to gather information about felt earthquakes:

Table 4. Summary of benefits interviewees identified from using a crisis crowdsourcing model

\begin{tabular}{|l|l|}
\hline \multicolumn{1}{|c|}{ Improvements and Benefits } & \multicolumn{1}{|c|}{ How... } \\
\hline Transparency \& Accountability & Increase in trust \\
Education \\
Citizen decision making \\
Progress visual \\
Updates (live vs. periodic) \\
Resource allocation \\
\hline Government-Citizen Communication & Timeliness \\
& Alerts and information dissemination \\
& Public engagement \\
Gathering feedback \\
Internal Communication & Sentiment analysis \\
\hline Enriching the dataset & Direct and fast \\
& Alternate routes \\
& Progress visual \\
& Resource allocation \\
\hline & Risk analysis \\
& Order of magnitude \\
& Situational reports \\
& Aid field crews \\
& Photos \\
& Geographic information \\
\hline
\end{tabular}


I mean, I can't overstate the component of catharsis people seem to feel. Like I said, people want to go out and talk to their neighbours after an earthquake, people that they've never talked to ever, for any other reason. And so that instinct is somewhat satisfied by people filling out a questionnaire and knowing that it's being used and that their experience was valuable. That's a catharsis that you just can't get any other way (Interviewee $G, 2015$ ).

The timeliness of communication during an emergency can also be improved by allowing governments to send out more accurate alerts more quickly, and monitor real-time information to facilitate a feedback loop of updating alerts based on incoming information.

In terms of internal communication, emergency management agencies already have systems in place to maximize communication between departments and response crews. Not all these systems fully integrate social media or crowdsourcing, and many do not update "on-the-fly" for response crews in the field. Interviewees suggested that adding crowdsourcing and live updates to their existing systems could improve response times, resource allocation, and overall situational awareness. In Canada, one county level CEMC described how social media was used to improve their response efforts and resource allocation:

If I can go back two winters ago where we had some, we had a very serious snow incident here that shut down many communities for several days, where people were posting that they had real issues with either no heating in their home, or no food for their children, we were able to take that information and act upon it to provide them emergency social services. (Interviewee A, 2015)

Closely tied to internal communication, crowdsourcing and social media can enrich the data that agencies are collecting for situational awareness and response by adding real-time photos and geographic information, which can help responders determine what resources are needed and where. One county-level emergency manager from Canada described how photos and geographic information from social media help at their agency's EOC:

Geographic attributes and photos of damage are priceless in the Emergency Operations Centre. When I gather my emergency control group and we're in a room trying to determine our priorities and determine the validity of the information that's coming in, knowing the geography, seeing photos of damage really allows us to determine the severity and allows us to mobilize resources faster than we would otherwise. (Interviewee A, 2015)

This is especially important for government agencies to utilize limited resources most appropriately. The added photos and geographic information can also be used to draw a fuller picture in the agencies' command reports, after-action reports, and situational reports.

\section{Crowdsourcing in the Disaster Management Cycle}

Discussions with interviewees revealed that crowdsourcing feeds into all phases of the disaster management cycle. Interviewees who practice crisis crowdsourcing indicated that the crowdsourcing process starts when a disaster occurs by first collecting information from the citizens on the ground for response and recovery efforts, and then using the information to learn from the event and inform future mitigation and preparedness efforts. The following analysis will start with examples that demonstrate the use of crisis crowdsourcing in the post-disaster phases (i.e. response and recovery shown in Figure 1). Afterwards, examples that illustrate how the information gathered from crisis crowdsourcing feed back into the pre-disaster phases (i.e. mitigation and preparedness in Figure 1) are presented and discussed. 


\section{Response and Recovery}

The response and recovery phases in the disaster management cycle occur after a disaster strikes, and are referred to here as the post-disaster phases. In the response phases, efforts are focused on conducting search and rescue operations and providing basic humanitarian needs for those impacted (Poser \& Dransch, 2010). After the initial response, the recovery phase begins in which repairs to damaged infrastructure and property are made, ensuring that those impacted by the disaster are provided with the appropriate means to restore their livelihoods (Poser \& Dransch, 2010). Much of the focus on crisis crowdsourcing has been in these post-disaster phases, particularly in the response phase. The interview results provide further support for this trend.

\section{Social Media and Passive Crowdsourcing}

Social media offers insight into the impact of a crisis on those involved. Interview results show that government agencies turn to social media to dispel rumors, reputation management, responding to calls for aid, enhancing situational awareness, monitoring citizen use of and response to official information (i.e. sentiment analysis), and for remote monitoring. Each of these uses apply to the post-disaster phases. Often, monitoring social media is used to keep track of false information during a disaster. An Executive Director of Public Safety Initiatives at the provincial level described how social media can be used by provincial governments in assuring that rumors are dispelled:

It's a great source of information, so you're looking to it from a sort of mining it for information, so an intelligence type use, but also to track the information for correctness of information. And when required we would correct wrong information. (Interviewee T, 2015)

The negative impacts of rumor spreading on social media can create unfounded fears amongst the impacted populations, as described by a Team Lead at the provincial level from Canada:

There was an extensive distribution offalse information, rumours, fake pictures on Twitter, Instagram and Facebook during Hurricane Sandy that helped, perhaps, create some concerns or unfounded fears among the people in the areas that were impacted by the storm. (Interviewee H, 2015)

By controlling false rumors, response and recovery can be improved by avoiding unnecessary spread of fear and panic, which can distract responders from the real impacts.

Results from the interviews revealed that one of the primary uses of social media is to enhance situational awareness. Situational awareness refers to understanding of unfolding events that are impacting many actors and "moving parts" (Vieweg et al., 2010). By enhancing and maintaining situational awareness, emergency management officials can implement more effective response plans and manage requests for information (Cameron et al., 2012). Interviewees indicated that social media is an essential tool in building situational awareness. One county-level official from Canada described how social media is used to "augment our situational awareness, and it's also used to gauge what the community needs are" (Interviewee P, 2015). Social media provides an opportunity for officials to identify community needs and adjust their response efforts. The same interviewee also used social media to monitor the "response to our response", and uses sentiment analysis to determine how their information is being propagated, which then helps assess the effectiveness of their agency's communications reach.

The situational awareness built from social media can be used to inform the EOC, to update alerts, or to inform actionable decisions, such as sending out response crews. For example, a countylevel CEMC from Canada monitored social media during a tornado-producing severe weather event. The interviewee followed reports of storm activity on Twitter and matched it up with alerts from Environment Canada, and used this to issue information over social media and email. At the provincial 
level, in Canada, situational awareness can improve information sharing between agencies, which can then inform decision-making:

[Social media] helps us build our situational awareness, and then what we do is we build a situation, we call it a common operating picture report, and then we disseminate that across government and to the affected communities. And so, the advantage of that is that report takes the information we're gathering from all sources, collates it, verifies the information and then we push it out to those [affected communities]. So, it's, everybody has a common understanding of what's going on and the information they have in their hands is verified reliable information that they can act on. (Interviewee T, 2015)

Building situational awareness is critical in the response and recovery phases. The focus of interviewees on using social media for situational awareness demonstrates how it can improve response efforts and decision making in emergency operations. Additionally, the widely accessible nature of social media and its large user base provides can build situational awareness as it enables agencies to partake in remote monitoring. Now, agencies from across the country (even internationally) can offer help in an unfolding, large-scale disaster. One participating county-level agency in Canada did this when they were asked to monitor social media for a large-scale flood disaster in another province:

During emergencies, we've used it locally when we've had events. We've also used it to assist other municipalities, so during the Calgary floods, our communications team actually used Sprout Social to monitor social media activity in the Calgary area. So that's really allowed us to capitalise on our abilities. We were completely unaffected by that incident, but able to help out. And then when we get inundated with an incident, we're able to call on our partners or other communities to help us monitor social media. So, it's very helpful. (Interviewee A, 2015)

\section{Active Crowdsourcing}

Building on the situational awareness theme, an active crowdsourcing application allows emergency management officials to visualize current ground conditions on a map, and identify the neighborhoods in most need of aid. This approach was used by a county-level agency in the USA. The agency uses a web-application for citizens to submit reports of storm damage and flooding (Figure 3). In an online reporting form, citizens select a damage level (e.g. moderate, major, destroyed) and a flood level (e.g. street level, inside home) for the county to assess damage. The application does not have a verification process, and the crowdsourced information is published "as is". Because of this, the agency does not use it for responding to individual reports, and instead uses it to build situational awareness.

Interviewees indicated that both passively and actively crowdsourced information can be included in situational reports. During the response and recovery phases, these reports are distributed amongst other impacted communities to maintain open communication and coordination between jurisdictions. They are also used to apply for disaster relief funds from higher-tiered agencies (i.e. the provincial/ state or federal government). This takes place in the recovery phase, when agencies and citizens are attempting to rebuild and are submitting insurance claims.

\section{Mitigation and Preparedness}

The mitigation and preparedness phases in the disaster management cycle (see Figure 1) focus on reducing risk and vulnerability to lessen disaster impacts. Mitigation involves continuous risk identification and analysis, and risk reduction through planning and education (Poser \& Dransch, 2010). Preparedness follows mitigation with direct planning of response protocols if a disaster were to strike; monitoring and forecasting of an approaching hazard is undertaken, and warning systems are implemented (Poser \& Dransch, 2010). While much of the focus in the crisis crowdsourcing realm 
Figure 3. The online damage reporting form used by a county-level government in the USA

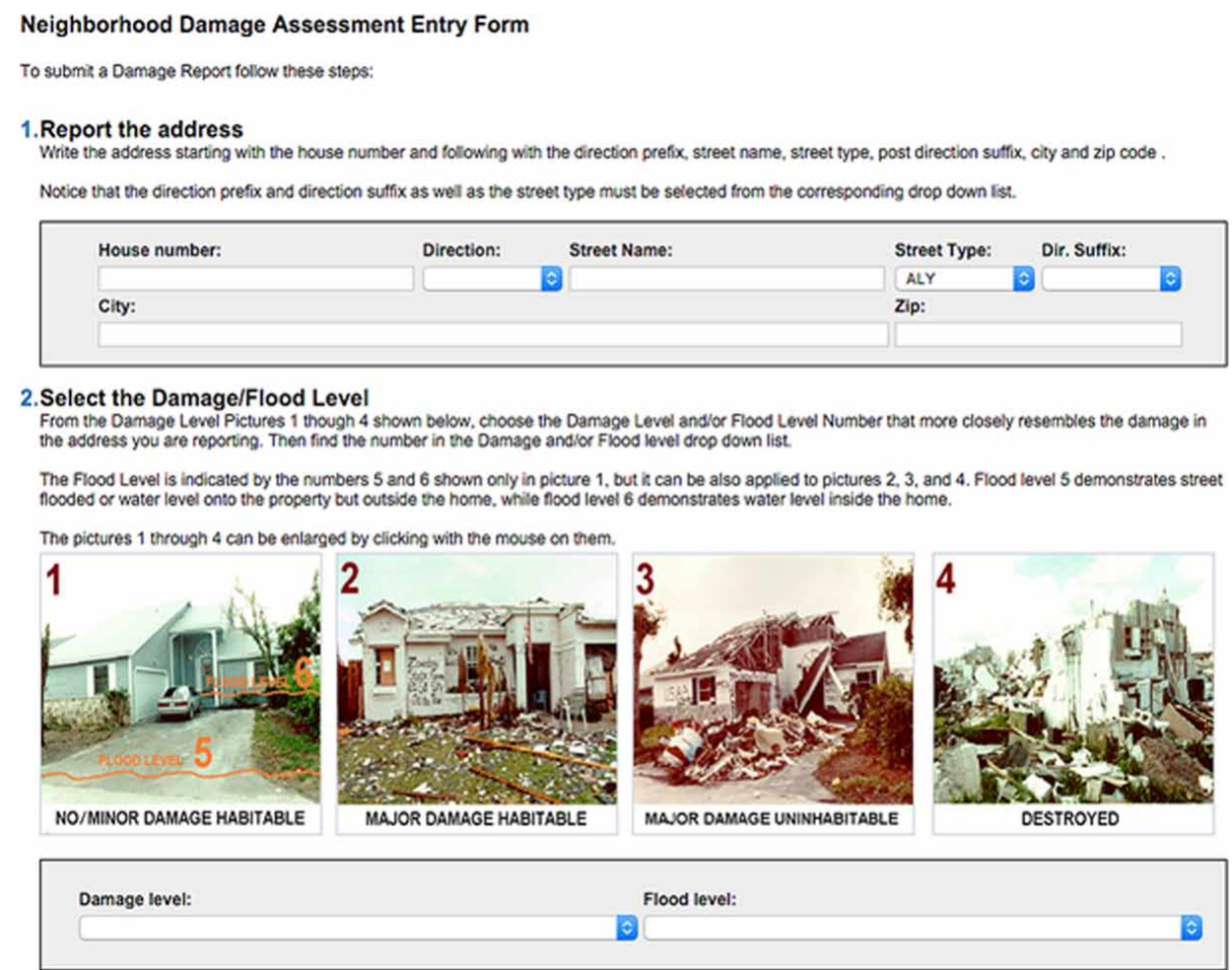

3.Submit your Neighborhood Damage Report

Please submit your Neighborhood Damage Repon by cilcking the SUBMIT button. Thank you for your cooperation!

has been on its use in the post-disaster phases, interviews with officials from both Canada and the USA revealed that it is also valuable in the pre-disaster phases.

\section{Social Media and Passive Crowdsourcing}

During the mitigation and preparedness phases, social media is used primarily as a government- tocitizen communication tool. Social media has proven to be useful in educating the public around proper emergency preparedness practices and for sending out alerts and warnings (i.e. severe weather, flooding, wildfire, etc.). It was described by one county-level official as being their agency's "dominant method" of communicating emergency information and alerts to the public. Interestingly, many interviewees focused on how social media has improved their information dissemination for increasing preparedness. This reflects the shifting focus in the emergency management realm from response and recovery to mitigation and preparedness. Interviewees determined that social media is highly effective for government information dissemination because it connects with many people at once, is accessed daily by public citizens, and is comparably fast:

It's just been fantastic, like I said, being able to reach out to that many people, being able to control our message, and not rely on the media to take a press release, add their information, their spin to it and get it to the public. So, to be able to actually directly communicate the message to that many people all at once is fantastic. (Interviewee A, 2015) 
... basically, as another form of information, so coming in information, but more as a tool for preparedness and education, so reaching out to the municipality. And if we know that we've got potential for a heat wave, so prior to the heatwave, in conjunction with the health unit, sending out reminders about how to protect yourself and be ready. (Interviewee K, 2015)

As an extension of information dissemination, social media can be used to understand the public's perception of and response to official emergency information. Government agencies want to ensure that their messages are being received and understood, otherwise they need to provide further instructions or clarification. Agencies can monitor social media for feedback on their awareness and preparedness initiatives, as one city-level official did during a special education session held during Emergency Preparedness Week in May of 2015. The feedback that officials received over social media confirmed there is value in hosting educational events.

In the USA, the federal government developed a passive crowdsourcing approach to earthquake monitoring by harvesting Twitter data. This application gathers qualitative descriptions of earthquakes experienced by Twitter users. For example, when the application was implemented in 2009 following the 2008 earthquake disaster in Wenchuan, China, the earthquake was detected on Twitter before seismologists could publish information based on earthquake data from seismometers. The Director of Operations from the federal agency described how this was possible:

How they detected this earthquake on Twitter before the seismologists published the information based on the earthquake data and this makes sense because, you know if you have seismometers a long ways away, the shaking waves won't get there, but if you have people closer they'll feel it faster and then feed that information, which travels at the speed of light and then you can get those tweets, so it's a matter of increasing the coverage of your sensors. (Interviewee C, 2015)

In response, the agency developed a Twitter harvesting system to detect earthquakes around the world, particularly in regions with sparse seismic networks. The early detection offers "a quick head's up that something's going on, and then a qualitative measure of the interest in that, and potentially the impacts of that earthquake" (Interviewee C, 2015). This application has evolved into a short-term earthquake alert system. Figure 4 shows a screenshot taken from the agency's Twitter feed of a recent earthquake that was detected. The tweet provides a quick warning about an earthquake situation unfolding so that the appropriate response agencies can prepare, supporting both immediate and short-term preparedness efforts.

\section{Active Crowdsourcing}

When considering active crowdsourcing, interview results indicate that while the crowdsourcing applications are typically used by citizens directly after an emergency, the information gathered can also be used to inform the pre-disaster phases. This is true for the federal-level crowdsourcing applications used in the USA and in Canada. In Canada, the federal government practices a unique

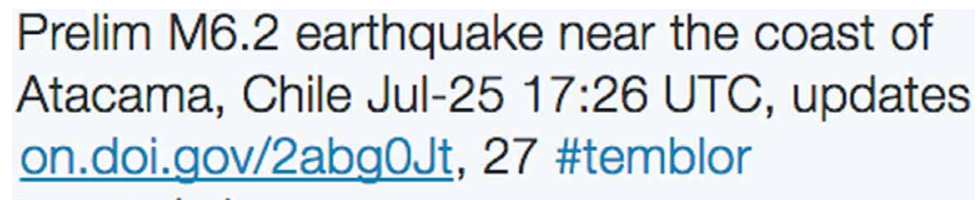


form of crowdsourcing developed in 1978, when a volunteer Weather Watch Program was created with an unlisted 1-800 phone number for registered volunteers (i.e. storm spotters) to report instances of severe weather. Since then, the program has evolved to allow volunteers to submit reports over telephone, email, and social media (see Figure 5). There is no specially developed application for volunteers to download or report $\mathrm{pn}$, but the process of collecting reports from the volunteers over the various mediums is well-defined and managed.

The primary use of this active crowdsourcing practice is in the mitigation and preparedness phases, with a more direct use in preparedness. The volunteer weather reports can be applied both in real-time and after an event to inform short-term and long-term preparedness, respectively. In real-time, the agency uses the reports from one geographic location to alert populations in another location as to what kind of severe weather is headed their way. Afterwards, the reports can still be "invaluable" for the agency's verification program by using the reports to evaluate the agency's performance in sending out their thousands of watches and warnings each year (Interviewee L, 2015). This crowdsourced information feeds into the short-term preparedness and mitigation of an event, as the agency uses reports to verify and update their warnings. In the long-term, the agency can use

Figure 5. Examples of severe weather reports posted on Twitter for the Canadian federal agency in a recent severe weather event

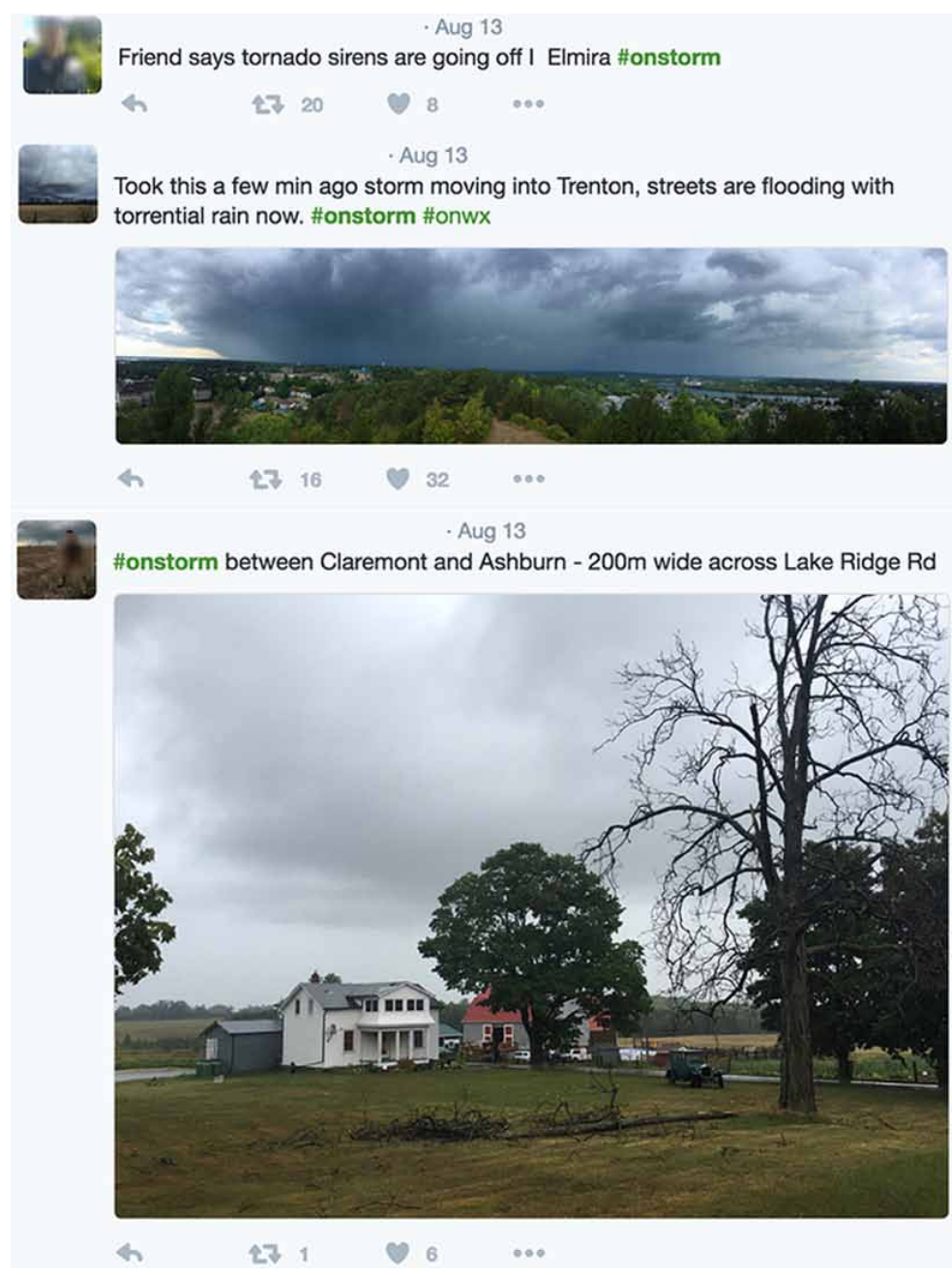


this information to continuously improve their monitoring and forecasting system, to understand how their alerts are being perceived and responded to.

The US federal government uses two active crowdsourcing applications for preparedness and mitigation efforts. The first application, called "Did You Feel It?" (DYFI?), is specifically designed for measuring earthquake intensity and evolved from a traditional paper survey method. The paper surveys were typically only conducted for significant earthquake events and excluded the minor, felt earthquakes that happen on a regular basis, and were only filled out by postmasters and sent back to the government agency. This resulted in major gaps in the data. When the survey was brought online in 1999 and automated, it became accessible to anyone with access to the internet, thus resulting in a more complete, global dataset for earthquakes of any intensity. The application is primarily used to depict the shaking intensity and distribution in map-form after an earthquake of any magnitude based on information submitted by citizens through an online form (Figure 6). These "shakemaps" and the global earthquake database is used to inform earthquake management:

Our job is really to do the science for which decisions are made whether they're long term planning or response. (Interviewee $G, 2015$ )

As the global database on felt earthquakes continues to grow, earthquake modeling and forecasting can be improved, further enabling mitigation efforts within earthquake hazard and risk management.

The second active crowdsourcing application implemented by the US federal agency included in this study, called "iCoast," aids in improving hurricane mitigation and preparedness. The initial idea of the application was based on using a large aerial imagery collection of coastlines before and after significant hurricane events. This application allows citizens to perform image analysis to improve modeling of coastal change processes caused by hurricanes. Citizens access the application through their computer's browser and are presented with aerial images of the eastern coast from before and after Hurricane Sandy, as shown in Figure 7. The citizens follow a step-by-step process to identify damage types caused by the hurricane.

It was found that iCoast provided an added benefit of raising hurricane hazard education and awareness. Taking the citizen through the entire process provided an opportunity for citizens to learn about the coastal hazards associated with hurricanes. Citizens living along the coast became more aware of the issues they may face on their coastal properties. The agency received feedback which outlined this:

We got some feedback from people who are participating and how they're starting to realize and learn what does coastal erosion mean? what are the issues that I need to be aware of living on the coast? and things like that. So, to some level it was educating people in a way where they're helping us but they're also learning how we are communicating our science. (Interviewee I, 2015)

There are two distinct uses for information produced from this project, both of which fit into the mitigation and preparedness phases: 1) to improve modelling of associated hurricane hazards such as coastal erosion, and 2) to provide an educational tool for contributors to learn about coastal hazards associated with hurricanes. Improved modelling can enhance efforts to reduce coastal erosion and flooding while the contributors who live on the coast can learn how their coastal properties are impacted. This application is enabling the US federal government to raise public interest towards hazard mitigation, and fuel voluntary mitigation practices at the individual level (Godschalk et al., 2003; Semenza et al., 2011).

The above findings demonstrate that information gathered from passive and active crowdsourcing can inform long-term and short-term mitigation and preparedness efforts. Study interviewees suggested that photographic and geographic information gathered through crowdsourcing can be used to inform 
Figure 6. A structured reporting form of felt earthquakes allows the agency to derive quantitative values from qualitative data

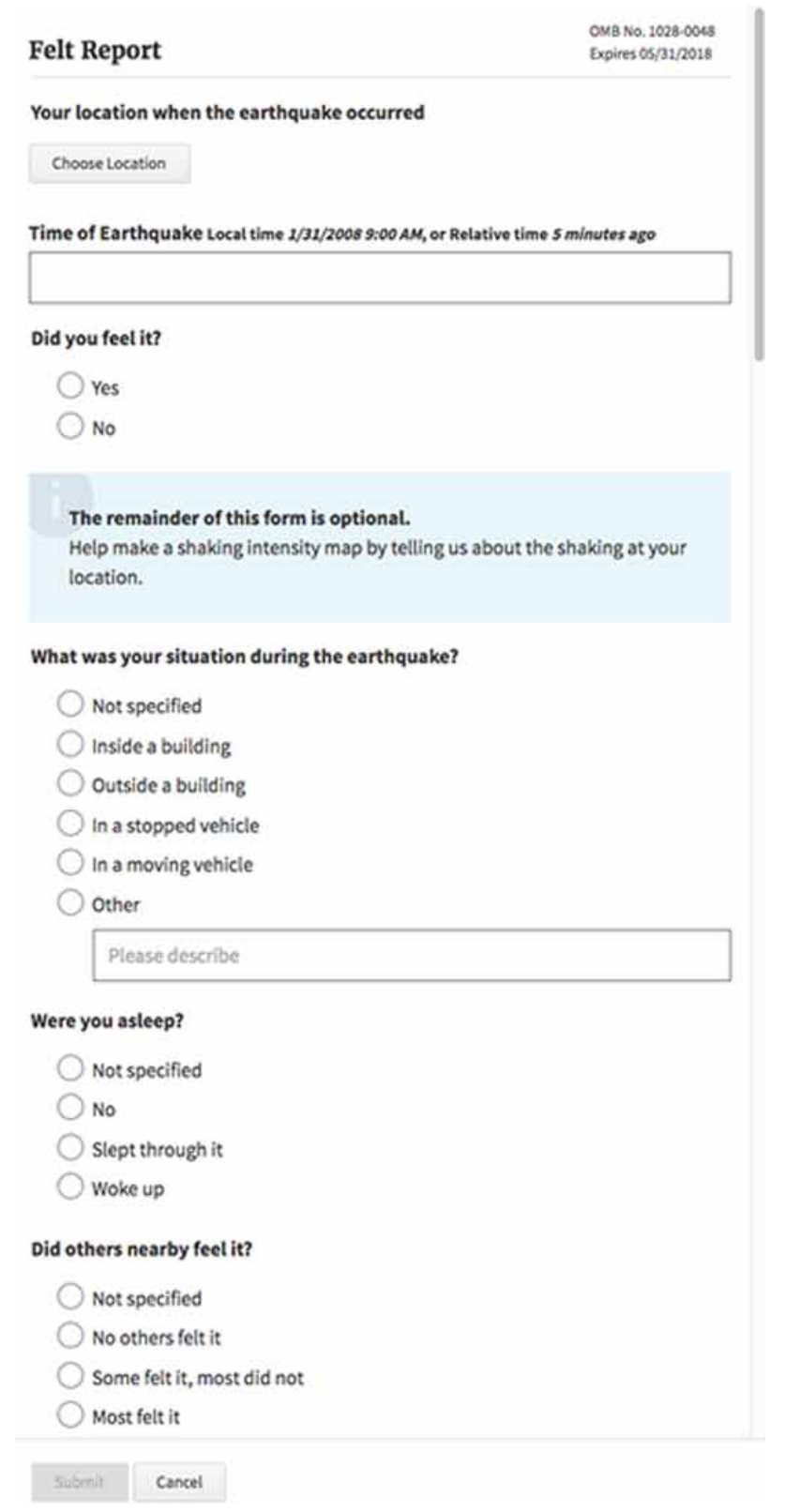

"after-action" reports. These reports are then used to learn from an incident, to identify what was done well and what could be done better in the future, thus improving mitigation and preparedness. They are also used to perform risk analysis, further enhancing mitigation efforts.

\section{Government Crisis Crowdsourcing as a Contributor Throughout the Disaster Management Cycle}

Interview results show that crisis crowdsourcing plays a role in all phases of the disaster management cycle. Moreover, there was a high-level of focus on using crowdsourcing information to further enhance 
Figure 7. Citizens are presented with a before and after aerial image along a section of the coastline to identify specific changes in the photos that may have resulted from Hurricane Sandy

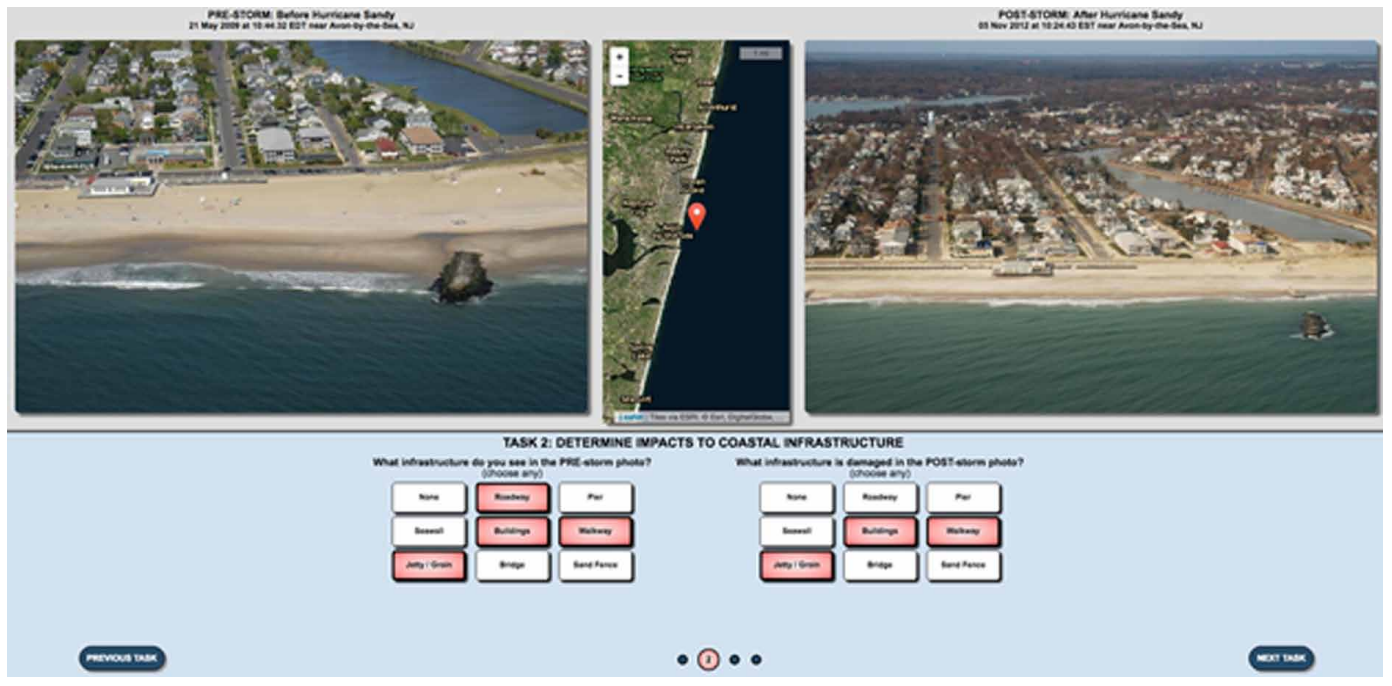

mitigation and preparedness efforts. The findings are summarized in an annotated diagram of the disaster management cycle (Figure 8). The diagram illustrates disaster management as a continuous cycle that flows between pre-disaster to post-disaster, and the experiences from the post-disaster phases are used for continuous improvement of mitigation and preparedness efforts.

The interview results reveal a pattern in the adoption and use of crisis crowdsourcing for each level of government. Participating agencies from the federal level appear to use crisis crowdsourcing for mitigation and preparedness, while local and county-level agencies use crowdsourcing for response and recovery. This may be because lower-tiered agencies experience the direct impacts of a given crisis event, while higher-tiered governments are concerned with providing appropriate support and resources to mitigate those impacts.

\section{CONCLUSION}

This study demonstrates the improvements that crisis crowdsourcing can add to current government emergency management operations. Until recently, research has been heavily focused on crisis crowdsourcing efforts by governments in the USA, however recent studies from Canada demonstrate the efforts that Canadian government agencies are taking towards crowdsourcing and social media adoption. This research characterizes the current state of crisis crowdsourcing amongst Canadian emergency management agencies. While some agencies in Canada have experimented with social media and found it to be beneficial, thus officially adding it into their routine operations, other Canadian agencies remain guarded, and are still assessing the costs and benefits associated with integrating into their operations. Results from those agencies in both Canada and the USA who have successfully adopted crisis crowdsourcing and social media shows that these technologies offer several benefits for emergency information communication between government and citizens.

This study is limited by some key factors. The primary data collection methods and sample size from both counties limits the extent to which the results can be generalized, as it is not a representative sample of all emergency management agencies in both countries. Accompanying surveys or questionnaires with the semi-structured interviews could enrich the data by gathering it in a standardized format, making it easier to identify trends. In addition, more sophisticated recruitment 
Figure 8. Crisis crowdsourcing fits into all four phases of the disaster management cycle

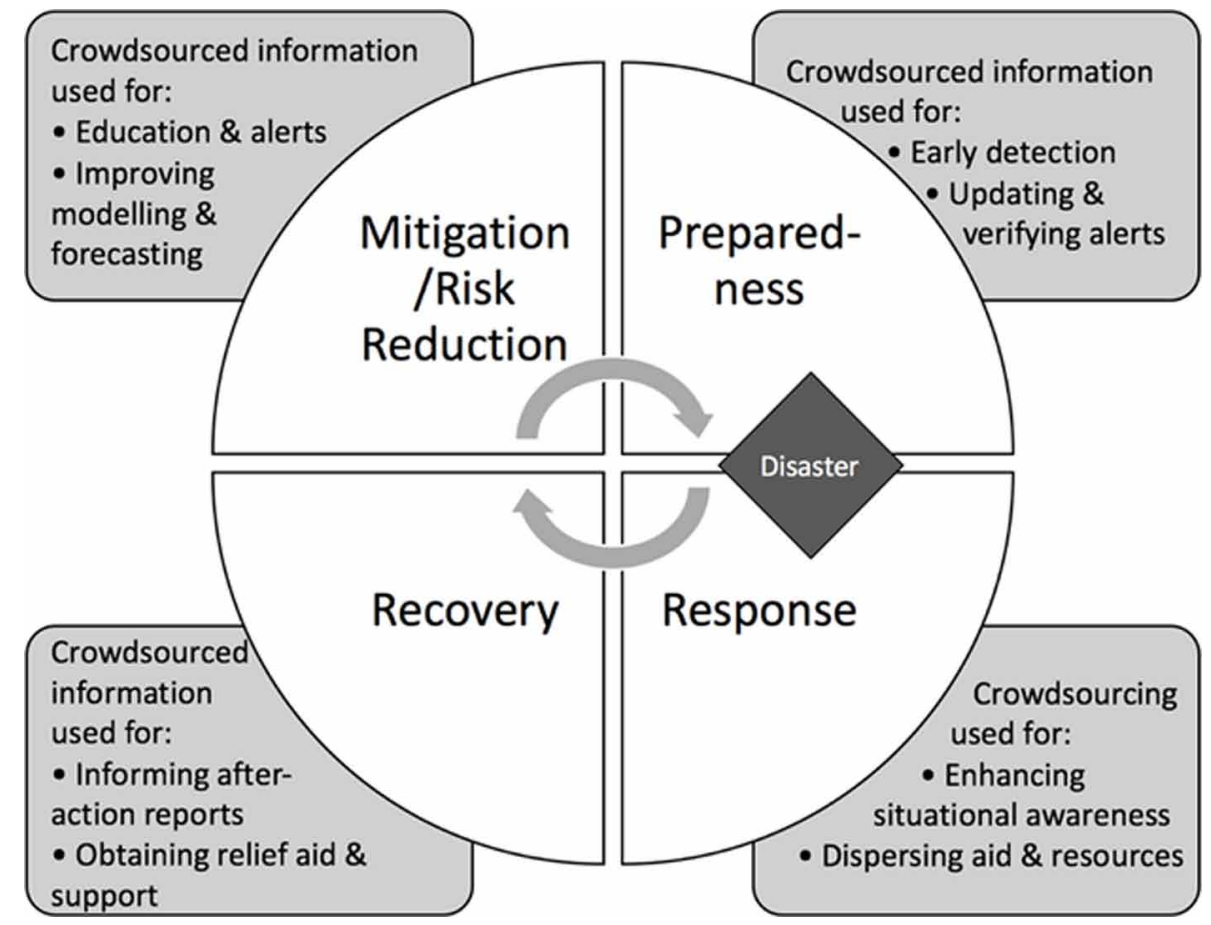

efforts (i.e. incentives, personalization of recruitment letters, etc.) could increase the response rate and overall sample size.

It is possible for some discrepancy to have occurred between telephone and in-person interviews, for example the inability to read body language and probe for more details, and time limitations which could potentially restrict in-depth discussion (Novick, 2008). However, telephone interviews do offer advantages for qualitative data collection, particularly for this study, such as decreased cost, communicating with professionals at various geographic locations that were, in various instances, several hours' flights away from the researcher's location, and maintaining a level of privacy and anonymity (Novick, 2008). When possible, it is preferred to conduct interviews in-person. However, in the case of this study, telephone interviews made it easier and cost-effective to schedule and conduct interviews with professionals across North America over the phone.

A lack of data pertaining to the interviewees' age, gender, and educational backgrounds and detailed roles (they provided a brief description of their role) potentially limits the analysis of this study. For example, during discussions with some interviewees and research colleagues the age of government officials arose as a potential barrier to the adoption of new technology, especially crowdsourcing. In addition, the educational background of the interviewees may have influenced their responses to the questions, such as their motivations and perceptions to adopting crisis crowdsourcing technologies. More data would allow for a more in-depth analysis of these issues.

Much like the shift in the disaster management literature from response and recovery to mitigations and preparedness (Chikoto et al., 2013; Christoplos et al., 2001), there is a shift in the crisis crowdsourcing literature from using crowdsourcing for post-disaster efforts, to exploring its use in the pre-disaster phases. Using data collected from both American and Canadian government agencies, this research determines that crisis crowdsourcing is currently applied in all phases of the disaster management cycle. Crisis crowdsourcing is directly used in the post-disaster phases, and the resulting information is indirectly used to improve mitigation and preparedness for future 
hazards. There is a clear gap in the direct application of crisis crowdsourcing in the mitigation and preparedness phases. Emergency management officials and scholars in this field have an opportunity to fill this gap through adopting crowdsourcing directly for mitigation and preparedness. For example, the iCoast application uses crowdsourcing for mitigation and preparedness. This can increase citizen awareness and education of hazards, which then drives improved mitigation and preparedness efforts on an individual level. 


\section{REFERENCES}

Adamski, S. (2013). Crowdsourcing Disasters and Social Engagement Multiplied. https://www.fema.gov/ blog/2013-08-02/crowdsourcing-disasters-and-social-engagement-multiplied

Avvenuti, M., Cimino, M. G., Cresci, S., Marchetti, A., \& Tesconi, M. (2016). A framework for detecting unfolding emergencies using humans as sensors. SpringerPlus, 5(1), 43.

Baum, R., Highland, L., Lyttle, P., Fee, J., Martinez, E., \& Wald, L. (2014). "Report a Landslide" A Website to Engage the Public in Identifying Geologic Hazards. In K. Sassa, P. Canuti, \& Y. Yin (Eds.), Landslide Science for a Safer Geoenvironment (pp. 95-100). Switzerland: Springer International Publishing. doi:10.1007/978-3319-04999-1_8

Beaulieu, A., Bégin, D., \& Genest, D. (2008). Community mapping and government mapping: Potential collaboration? In Proceedings of the Symposium of ISPRS Commission I, Calgary, Alberta.

Bird, D., Ling, M., \& Haynes, K. (2012). Flooding Facebook-the use of social media during the Queensland and Victorian floods. Australian Journal of Emergency Management, 27, 27.

Brabham, D. (2013). Using Crowdsourcing In Government. IBM Center for The Business of Government.

Brady, D., \& Webb, N. (2013). Communicating Bushfire Safety in Australia: The Challenge for Government of Increasing Community Participation. Asia Pacific Media Educator, 23(2), 351-365. doi:10.1177/1326365X13517191

Burns, R., \& Shanley, L. A. (2012). Connecting Grassroots to Government for Disaster Management. The Wilson Center.

Cameron, M. (2012). Tapping into Social Media to Build Emergency Situation Awareness.

Cameron, M., Power, R., \& Robinson, B. (2012). Emergency Situation Awareness from Twitter for Crisis Management. In Proceedings of WWW 2012 (Companion), Lyon, France (pp. 695-698). doi:10.1145/2187980.2188183

Castellanos, A., Castillo, A., Gudi, A., \& Lee, R. (2013). Emergency planning and visualization: the case of Miami-Dade County's Emergency Operations Center (pp. 171-182).

Charalabidis, Y. N., Loukis, E., Androutsopoulou, A., Karkaletsis, V., \& Triantafillou, A. (2014). Passive crowdsourcing in government using social media. Transforming Government: People. Process and Policy, 8, 283-308.

Chikoto, G., Sadiq, A.-A., \& Fordyce, E. (2013). Disaster mitigation and preparedness comparison of nonprofit, public, and private organizations. Nonprofit and Voluntary Sector Quarterly, 42(2), 391-410. doi: $10.1177 / 0899764012452042$

Christoplos, I., Mitchell, J., \& Liljelund, A. (2001). Re-framing risk: The changing context of disaster mitigation and preparedness. Disasters, 25(3), 185-198. doi:10.1111/1467-7717.00171 PMID:11570333

Cotter, D., Gusty, D., Caplan, M., Booth, J., Thomas, J., Cohen, S. E., \& O'Donnell, D. et al. (2015). CanadaU.S. Enhanced Resiliency Experiment (CAUSE III) (DHS S\&T Report). Department of Homeland Security (DHS) Science and Technology Directorate (S\&T) First Responders Group, Defence Research and Development Canada - Centre for Security Science. DRDC CSS.

Department of Energy, 2014. Energy Department Launches Mobile App for Energy Emergencies.

Earle, P., Bowden, D., \& Guy, M. (2012). Twitter earthquake detection: Earthquake monitoring in a social world. Annals of Geophysics, 54.

Estelles-Arolas, E., \& Gonzalez-Ladron-de-Guevara, F. (2012). Towards an integrated crowdsourcing definition. Journal of Information Science, 38(2), 189-200. doi:10.1177/0165551512437638

Flew, T., Bruns, A., Burgess, J., Ben-Harush, O., Potter, E., \& Newton, J. (2015). Support Frameworks for the Use of Social Media by Emergency Management Organisations (Policy Report). Brisbane, Australia: QUT Digital Media Research Centre. 
Fraustino, J. D., Liu, B., \& Jin, Y. (2012). Social media use during disasters: A review of the knowledge base and gaps. START, College Park, MD, USA.

Gao, H., Barbier, G., \& Goolsby, R. (2011). Harnessing the crowdsourcing power of social media for disaster relief. IEEE Intelligent Systems, 26(3), 10-14. doi:10.1109/MIS.2011.52

Godschalk, D. R., Brody, S., \& Burby, R. (2003). Public Participation in Natural Hazard Mitigation Policy Formation: Challenges for Comprehensive Planning. Journal of Environmental Planning and Management, 46(5), 733-754. doi:10.1080/0964056032000138463

Goodchild, M., \& Glennon, J. A. (2010). Crowdsourcing geographic information for disaster response: A research frontier. International Journal of Digital Earth, 3(3), 231-241. doi:10.1080/17538941003759255

Haworth, B. (2016). Emergency management perspectives on volunteered geographic information: Opportunities, challenges and change. Computers, Environment and Urban Systems, 57, 189-198. doi:10.1016/j. compenvurbsys.2016.02.009

Haworth, B., \& Bruce, E. (2015). A Review of Volunteered Geographic Information for Disaster Management. Geography Compass, 5(5), 237-250. doi:10.1111/gec3.12213

Hiltz, S. R., Kushma, J., \& Plotnick, L. 2014. Use of social media by US public sector emergency managers: Barriers and wish lists. In Proceedings of ISCRAM.

Hossain, M., \& Kauranen, I. (2015). Crowdsourcing: A comprehensive literature review. Strategic Outsourcing. International Journal (Toronto, Ont.), 8, 2-22.

Hughes, A., Palen, L., 2012. The Evolving Role of the Public Information Officer: An Examination of Social Media in Emergency Management. Journal of Homeland Security and Emergency Management 9.

Johnson, P.A., (2017) Models of direct editing of government spatial data: Challenges and constraints to the acceptance of contributed data. Cartography and Geographic Information Science. 44(2), 128-138.

Johnson, P., \& Sieber, R. (2013). Situating the Adoption of VGI by Government. In D. Sui, S. Elwood, \& M. Goodchild (Eds.), Crowdsourcing Geographic Knowledge (pp. 65-81). Dordrecht: Springer Netherlands. doi:10.1007/978-94-007-4587-2_5

Kaminska, K., Dawe, P., Rutten, B. (2013). Social Media for Emergency Management Expert Roundtable Workshop: Summary of Findings. DRDC CSS TN 46.

Kaplan, A., \& Haenlein, M. (2010). Users of the world, unite! The challenges and opportunities of Social Media. Business Horizons, 53(1), 59-68. doi:10.1016/j.bushor.2009.09.003

Koch, G., Füller, J., \& Brunswicker, S. (2011). Online crowdsourcing in the public sector: how to design open government platforms. In Online Communities and Social Computing (pp. 203-212). Springer. doi:10.1007/9783-642-21796-8_22

Laskey, K. (2013). Crowdsourced Decision Support for Emergency Responders. In Proceedings of the 18th International Command and Control Research and Technology Symposium.

Latonero, M., \& Shklovski, I. (2011). Emergency Management, Twitter, and Social Media Evangelism. International Journal of Information Systems for Crisis Response and Management, 3(4), 1-16. doi:10.4018/ jiscrm.2011100101

Lauriault, T., \& Mooney, P. (2014). Crowdsourcing: A Geographic Approach to Public Engagement. https:// papers.ssrn.com/sol3/papers.cfm?abstract_id=2518233

Lindsay, B. (2011). Social media and disasters: Current uses, future options, and policy considerations. DC: Congressional Research Service Washington.

Litchfield, H. (2015). Grundy County, Ill., Emergency Management Agency Introduces Phone App. Morris Daily Herald.

Liu, S. (2014). Crisis Crowdsourcing Framework: Designing Strategic Configurations of Crowdsourcing for the Emergency Management Domain. Computer Supported Cooperative Work. CSCW. 
Lodge, M., \& Wegrich, K. (2015). Crowdsourcing and regulatory reviews: A new way of challenging red tape in British government?. Regulation \& Governance, 9(1), 30-46.

Loukis, E., \& Charalabidis, Y. (2015). Active and Passive Crowdsourcing in Government. In M. Janssen, M. Wimmer, \& A. Deljoo (Eds.), Policy Practice and Digital Science (pp. 261-289). Cham: Springer International Publishing. doi:10.1007/978-3-319-12784-2_12

Meier, P. (2012). Big Data for Development: Challenges and Opportunities. http://www.unglobalpulse.org/sites/ default/files/BigDataforDevelopment-UNGlobalPulseJune2012.pdf

Morton, M., \& Levy, J. L. (2011). Challenges in Disaster Data Collection during Recent Disasters. Prehospital and Disaster Medicine, 26(03), 196-201. doi:10.1017/S1049023X11006339 PMID:22107771

Novick, G. (2008). Is there a bias against telephone interviews in qualitative research? Research in Nursing \& Health, 31(4), 391-398. doi:10.1002/nur.20259 PMID:18203128

Palen, L., Vieweg, S., Liu, S., \& Hughes, A. (2009). Crisis in a Networked World: Features of Computer-Mediated Communication in the April 16, 2007, Virginia Tech Event. Social Science Computer Review, 27(4), 467-480. doi: $10.1177 / 0894439309332302$

Paton, D. (2003). Disaster preparedness: A social-cognitive perspective. Disaster Prevention and Management, 12(3), 210-216. doi:10.1108/09653560310480686

Paton, D., \& Johnston, D. (2001). Disasters and communities: Vulnerability, resilience and preparedness. Disaster Prevention and Management, 10(4), 270-277. doi:10.1108/EUM000000005930

Poser, K., \& Dransch, D. (2010). Volunteered Geographic Information for Disaster Management with Application to Rapid Flood Damage Estimation. Geomatica, 64, 89-98.

Roche, S., Propeck-Zimmermann, E., \& Mericskay, B. (2011). GeoWeb and crisis management: Issues and perspectives of volunteered geographic information. GeoJournal, 78(1), 21-40. doi:10.1007/s10708-011-9423-9

San Su, Y., Wardell III, C., \& Thorkildsen, Z. (2013). Social media in the emergency management field. CAN Analysis and Solutions, Alexandria, VA.

Schellong, A., \& Langenberg, T. 2007. Managing citizen relationships in disasters: Hurricane Wilma, 311 and Miami-Dade County. In Proceedings of the 40th Annual Hawaii International Conference on System Sciences HICSS '07 (pp. 96-96).

Semenza, J. C., Ploubidis, G. B., \& George, L. A. (2011). Climate change and climate variability: Personal motivation for adaptation and mitigation. Environmental Health, 10(1), 1. doi:10.1186/1476-069X-10-46 PMID:21600004

Starbird, K. (2012). Crowdwork, crisis and convergence: How the connected crowd organizes information during mass disruption events (Doctoral dissertation, University of Colorado).

Starbird, K., \& Palen, L. (2011). "Voluntweeters": Self-Organizing by Digital Volunteers in Times of Crisis. In Proceedings of the SIGCHI Conference on Human Factors in Computing Systems. New York, New York, USA (pp. 1071-1080).

Starbird, K., \& Stamberger, J. (2010). Tweak the tweet: Leveraging microblogging proliferation with a prescriptive syntax to support citizen reporting http://repository.cmu.edu/silicon_valley/41/

Taylor, M., Wells, G., Howell, G., \& Raphael, B. (2012). The role of social media as psychological first aid as a support to community resilience building. Australian Journal of Emergency Management, 27, 20.

Tong, Y., Cao, C. C., Zhang, C. J., Li, Y., \& Chen, L. (2014). CrowdCleaner: Data cleaning for multi-version data on the web via crowdsourcing. In Proceedings of the 2014 IEEE 30th International Conference on Data Engineering (ICDE) (pp. 1182-1185).

Vieweg, S., Hughes, A., Starbird, K., \& Palen, L. (2010). Microblogging During Two Natural Hazards Events: What Twitter May Contribute to Situational Awareness. In Proceedings of the 2SIGCHI Conference on Human Factors in Computing Systems (pp. 1079-1088). 
Vieweg, S., Palen, L., Liu, S., Hughes, A., \& Sutton, J. (2008). Collective intelligence in disaster: An examination of the phenomenon in the aftermath of the 2007 Virginia Tech shootings. In Proceedings of the Information Systems for Crisis Response and Management Conference (ISCRAM).

Virtual Social Media Working Group, DHS First Responders Group. (2014). Using Social Media for Enhanced Situational Awareness and Decision Support. https://www.dhs.gov/science-and-technology/first-responders

Wald, D., Quitoriano, V., Dengler, L., \& Dewey, J. (1999). Utilization of the Internet for rapid community intensity maps. Seismological Research Letters, 70(6), 680-697. doi:10.1785/gssrl.70.6.680

Wald, D., Quitoriano, V., \& Dewey, J. (2011). Usgs “Did You Feel It?” Community Internet Intensity Maps: Macroseismic Data Collection Via the Internet. In Proceedings of the First European Conference on Earthquake Engineering and Seismology.

Zhang, D., Zhou, L., \& Nunamaker, J. Jr. (2002). A knowledge management framework for the support of decision making in humanitarian assistance/disaster relief. Knowledge and Information Systems, 4(3), 370-385. doi:10.1007/s101150200012

Zook, M., Graham, M., Shelton, T., \& Gorman, S. (2010). Volunteered Geographic Information and Crowdsourcing Disaster Relief: A Case Study of the Haitian Earthquake. World Medical \& Health Policy, 2(2), 6-32. doi:10.2202/1948-4682.1069

Sara E. Harrison is a graduate from the Geography and Environmental Management program at the University of Waterloo, with a specialization in Geomatics. Broad interests lie in GIS, VGI, emergency and disaster management.

Peter Johnson is an Assistant Professor in the Department of Geography and Environmental Management at the University of Waterloo. His research expertise is in the application and evaluation of geospatial technologies, including open data, the geospatial web, mobile devices, crowdsourcing, and volunteered geographic information 